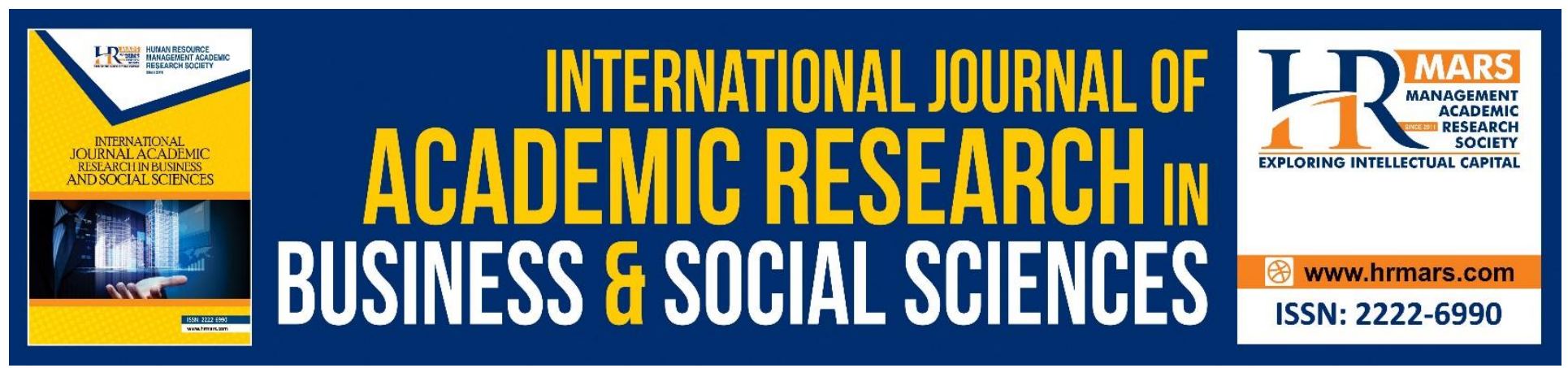

\title{
Strategic Development of Flipped Framework on Educators and Learning Constructs for ESL Context: The Experts' Agreement
}

Mohammad Musab Azmat Ali, Melor Md Yunus, Harwati Hashim, Azwin Arif Abdul Rahim, Nor Yazi Khamis

To Link this Article: http://dx.doi.org/10.6007/IJARBSS/v9-i3/5805

DOI: $10.6007 /$ IJARBSS/v9-i3/5805

Received: 17 Feb 2019, Revised: 29 Feb 2019, Accepted: 1 March 2019

Published Online: 27 March 2019

In-Text Citation: (Ali, Yunus, Hashim, Rahim, \& Khamis, 2019)

To Cite this Article: Ali, M. M. A., Yunus, M. M., Hashim, H., Rahim, A. A. A., \& Khamis, N. Y. (2019). Strategic Development of Flipped Framework on Educators and Learning Constructs for ESL Context: The experts' agreement. International Journal of Academic Research Business and Social Sciences, 9(3), 1414-1422.

Copyright: (c) 2019 The Author(s)

Published by Human Resource Management Academic Research Society (www.hrmars.com)

This article is published under the Creative Commons Attribution (CC BY 4.0) license. Anyone may reproduce, distribute, translate and create derivative works of this article (for both commercial and non-commercial purposes), subject to full attribution to the original publication and authors. The full terms of this license may be seen at: http://creativecommons.org/licences/by/4.0/legalcode

Vol. 9, No. 3, 2019, Pg. 1414 - 1422

http://hrmars.com/index.php/pages/detail/IJARBSS

JOURNAL HOMEPAGE

Full Terms \& Conditions of access and use can be found at http://hrmars.com/index.php/pages/detail/publication-ethics 


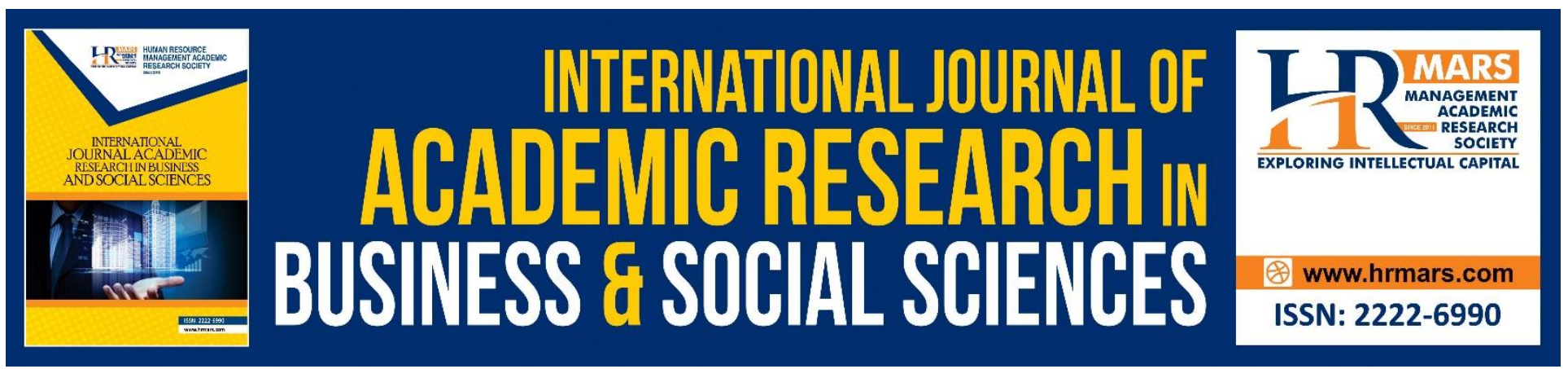

\title{
Strategic Development of Flipped Framework on Educators and Learning Constructs for ESL Context: The Experts' Agreement
}

\author{
Mohammad Musab Azmat Ali, Melor Md Yunus, Harwati Hashim, \\ Azwin Arif Abdul Rahim, Nor Yazi Khamis \\ Universiti Malaysia Pahang, Universiti Kebangsaan Malaysia, Universiti Kebangsaan \\ Malaysia, Universiti Malaysia Pahang, Universiti Malaysia Pahang
}

\begin{abstract}
The flip learning approach has been accepted by numerous studies as a strategic approach in implementing technological-based classroom environments. Concurrently, Ministry of Education Malaysia is introducing the national educational blueprint for higher education with the focus on heavy investment in developing Blended learning environments at tertiary institutions. This poses a conundrum of how best to implement such environments effectively. Hence, much researches needed to be empirically done to prove the effectiveness of a specific Blended learning approach for an ESL context. This paper aims to ascertain the required constructs in developing a framework for flipped learning in an ESL environment. The study utilized Fuzzy Delphi method to gather and analyze viewpoints of 18 experts from the relevant fields. An online questionnaire was developed to gather the experts' agreement towards four educators and learning related constructs namely 'Flexible Environments'; 'Shift in Learning Culture'; 'Intentional Content'; 'Professional Educators'; and 42 items gathered from the literature. The FDM analysis rejected six of the items; finalizing the framework with 36 items. The framework is beneficial to ESL educators, learners and developers of technology-based learning methods
\end{abstract}

Keywords: Flip Learning Approach, Blended Learning, Framework, ESL Context, Strategic Development

\section{Introduction}

Education of the $21^{\text {st }}$ century is strategically changing where technology has become a major deciding factor in determining meaningful and successful education to millennials students (Malganova \& Rahkimova, 2016). These students are more comfortable to be engaged in technology, which evidently led to tech-based educational approaches like E-learning, blended learning, and flip learning (Kenna 2014; Embi 2014; Hamdan et al. 2013). Particularly at tertiary education level, these digital technology-based approaches are widely used as media to facilitate meaningful learning 
experience (Sankey \& Hunt, 2013; Einfeld, 2013), through various forms of approaches with interaction and content for different learning styles (MOE, 2015). Flip learning is one of such teaching approaches that has the flexibility and independent disposition to jive well with the use of technology in education (Harun \& Hussin, 2017). Some experts believe that the approach allows for a cornucopia of pedagogical approaches to be implemented resulting in a range of methods that is tailor-suited to each students' learning styles (Baepler, Walker \& Driessen, 2014). Juhary and Amir (2014), and Bergmann \& Sams (2014), assert that a number of past studies has proven the ability of flip learning approach in engaging students to be self-dependent learners. Nevertheless, there is a minimal empirical proof of the existence of perimeters to effectively use of flip learning approach in a specific educational environment (Baepler et al., 2014; Lowell et al., 2013; Chen, Wang, \& Chen, 2014; O'Flaherty \& Phillips, 2015). The need for such a study that investigates the development of a parameter for flip learning approach is paramount, as the approach is getting attention and momentum as a practical approach to implement technology in education internationally and in Malaysia ( Juhary \& Amir 2015). The introduction of the National Educational Blueprint for Higher Learning in Malaysia, which has a specific focus on making technology-based education as its mainstay (2014), propels the need for this investigation that looks at the development of a parameter to effectively use the flip learning approach In a specific context. Therefore, this study aims to determine the required constructs for a strategic development of a flip learning framework in an ESL context through experts' agreement.

\section{Literature Review}

Past studies of investigations of the Flip learning approach has mainly concentrated on the improvements of academic performance and students' behavior and motivation to learn. Previous Studies done researchers mainly focuses on how the flip learning approach has improved students' engagement and academic performance (Embi, 2014). Studies done on flipped learning approach by researchers like Butt (2014), Walter-perez \& Dong (2012) found that the approach enhances students' academic performances in the lessons compared to conventional approaches. Furthermore, Bergmann \&Sams (2012), Berret (2012), and Osman, Jamaludin \& Mokhtar 2014, among other researchers have noted that the flip learning approach also improves the implementation of higher-order thinking skills among students as, the approach hinges on the fact that learning is personal, and that learning happens in active, and interactive environments.

The majority of studies on Flip learning concentrate on the students' perception of the approach and its effect in their learning process. These studies are conducted in various educational context. Studies such as Mclaughlin et. al (2013), which looked at the perception of pharmacology students by comparing the medium of instruction, between the Flip learning approach and conventional approaches, generally reported a positive outlook of students learning using the Flip learning approach. Other studies reported results of similar ilk in different contexts as well such as Butt (2014) Actuary, Tally \& Scherer (2013) Psychology, and Deslauriers, Schelew \& Wieman, (2011) Physics. What all these studies fail to do is to base their studies on a particular framework or a context-based framework to guide them to a much valid finding. This absence of framework can be explained in the novelty of the approach, as not much research has been done on identifying and describing factors 
INTERNATIONAL JOURNAL OF ACADEMIC RESEARCH IN BUSINESS AND SOCIAL SCIENCES

Vol. 9, No. 3, March, 2019, E-ISSN: 222 2-6990 @ 2019 HRMARS

that ensure effective implementation of the approach in each respective field. This research tries to answer such a paucity in literature by identifying and testing factors meted by Hamdan et. al (2013) as the basis for the development of a flipped learning framework in an ESL context.

\section{Methodology}

The study employed Fuzzy Delphi Method (FDM) in analyzing and interpreting the data gathered from the experts' responses toward the items in an online questionnaire. The experts' agreement toward the constructs is invaluable as their professional experience and knowledge on the subject matter is be pivotal in determining the right constructs for the framework. The data were analyzed in terms of the experts' acceptance or rejection of the items to measure the constructs it represents. A 5-Likert scale of agreement, from 'Strongly Disagree' (1) to 'Strongly Agree' (5) was used to rate the experts' agreement toward the questionnaire item. Apparently, four constructs, which are related to educators and learning, were identified from the works of Hamdan et al. (2013). These four constructs comprised of 42 items of statements and were presented in an online questionnaire using Google docs. The link of the questionnaire was emailed to 22 identified experts in educational technology, or ESL and educational technology. 18 experts provided their responses towards the statements which were then analysed using FDM. The quantitative analysis concerns with the (d) threshold value of the items and constructs, and the percentage of experts' agreement towards the acceptance and rejection of items and constructs.

\section{Results}

Each of the four constructs was represented by several items. These four constructs focused on educators and learning requirements in using flip learning approach. These constructs were the foundation for the 42 items developed, and analysed using FDM. For deliberation and discussion of the findings, the (d) threshold values were benchmarked at $\geq 0.2$ for the constructs and items, and $75 \%$ the percentage of experts' agreement. A summary of the constructs and the number of items are: Flexible Environments (8 items), Shift in Learning Culture (9 items), Intentional Content (10 Items), and Professional Educators (15 items).

The first of the construct was the 'Flexible Environments' (FE) which had eight items (Table 2). The individual item (d) threshold value for FE1 (0.200), FE2 (0.150), FE3 (0.186), FE4 (0.169), FE6 (0.212), FE7 (0.167), and FE8 (0.147) respectively. Furthermore, the percentage of experts' agreement for the items were 100\% (FE2 and FE7), 94.44\% (FE4 and FE6), and 88.88\% (FE1; FE3 and FE8) respectively. These items were agreed by the experts as they have met the benchmark value and the percentage of experts' agreement. However, item FE5 was rejected as the (d) threshold value of 0.212 and its percentage of experts' agreement 33\% did not meet the targeted value. In overall, 'Flexible environment' construct had a (d) threshold value of 0.180 and the overall experts' agreement percentage of $86.1 \%$. 
INTERNATIONAL JOURNAL OF ACADEMIC RESEARCH IN BUSINESS AND SOCIAL SCIENCES

Vol. 9, No. 3, March, 2019, E-ISSN: 222 2-6990 ¿ 2019 HRMARS

Table 2

FLEXIBLE ENVIRONMENT (FE) CONSTRUCT THRESHOLD VALUE (D), PERCENTAGE OF EXPERTS' CONSENSUS, AND DEFUZZIFICATION

\begin{tabular}{|c|c|c|c|c|c|c|c|c|}
\hline \multirow{2}{*}{ EXPERT } & \multicolumn{8}{|c|}{ ITEM } \\
\hline & FE1 & FE2 & FE3 & FE4 & FE5 & FE6 & FEZ & FE 8 \\
\hline 1 & 0.2 & 0.1 & 0.2 & 0.1 & 0.3 & 0.2 & 0.1 & 0.1 \\
\hline 2 & 0.1 & 0.2 & 0.4 & 0.2 & 0.3 & 0.1 & 0.2 & 0.1 \\
\hline 3 & 0.1 & 0.2 & 0.1 & 0.2 & 0.3 & 0.1 & 0.1 & 0.5 \\
\hline 4 & 0.2 & 0.1 & 0.1 & 0.1 & 0.3 & 0.1 & 0.2 & 0.2 \\
\hline 5 & 0.1 & 0.1 & 0.2 & 0.2 & 0.3 & 0.2 & 0.1 & 0.1 \\
\hline 6 & 0.2 & 0.1 & 0.2 & 0.1 & 0.0 & 0.2 & 0.2 & 0.1 \\
\hline 7 & 0.2 & 0.1 & 0.4 & 0.1 & 0.3 & 0.1 & 0.1 & 0.1 \\
\hline 8 & 0.2 & 0.1 & 0.2 & 0.1 & 0.0 & 0.1 & 0.1 & 0.1 \\
\hline 9 & 0.2 & 0.1 & 0.2 & 0.1 & 0.3 & 0.2 & 0.1 & 0.1 \\
\hline 10 & 0.1 & 0.2 & 0.1 & 0.2 & 0.3 & 0.4 & 0.2 & 0.2 \\
\hline 11 & 0.1 & 0.2 & 0.4 & 0.1 & 0.3 & 0.1 & 0.2 & 0.5 \\
\hline 12 & 0.1 & 0.2 & 0.1 & 0.5 & 0.3 & 0.1 & 0.2 & 0.2 \\
\hline 13 & 0.7 & 0.2 & 0.1 & 0.1 & 0.0 & 0.2 & 0.1 & 0.1 \\
\hline 14 & 0.4 & 0.2 & 0.1 & 0.2 & 0.0 & 0.1 & 0.2 & 0.2 \\
\hline 15 & 0.1 & 0.1 & 0.2 & 0.1 & 0.3 & 0.2 & 0.1 & 0.1 \\
\hline 16 & 0.2 & 0.1 & 0.2 & 0.1 & 0.3 & 0.2 & 0.1 & 0.1 \\
\hline 17 & 0.2 & 0.1 & 0.1 & 0.2 & 0.0 & 0.2 & 0.1 & 0.1 \\
\hline 18 & 0.2 & 0.2 & 0.1 & 0.2 & 0.0 & 0.1 & 0.1 & 0.1 \\
\hline d value for each item & 0.200 & 0.150 & 0.186 & 0.169 & 0.212 & 0.167 & 0.147 & 0.184 \\
\hline $\mathrm{d}$ value of construct & \multicolumn{8}{|c|}{0.177} \\
\hline No. of Item $d \leq 0.2$ & 16 & 18 & 16 & 17 & 6 & 17 & 18 & 16 \\
\hline$\%$ of Item $\mathrm{d} \leq 0.2$ & 88.88 & 100 & 88.88 & 94.44 & 33.33 & 94.44 & 100 & 88.88 \\
\hline$\%$ of Construct & \multicolumn{8}{|c|}{86.10} \\
\hline Fuzzy Evaluation & 12.000 & 12.800 & 11.600 & 12.600 & \multirow{3}{*}{ Rejected } & 12.200 & 13.000 & 12.800 \\
\hline Average of Fuzzy No. & 0.667 & 0.711 & 0.644 & 0.700 & & 0.678 & 0.722 & 0.711 \\
\hline Rank & 6 & 2 & 7 & 4 & & 5 & 1 & 3 \\
\hline
\end{tabular}

Table 3 presents the results of FDM for the 'Shift in Learning Culture' (LC) construct. The individual items' (d) threshold values for LC1, LC2, LC3, LC4, LC5, LC6, LC8, and LC9 between 0.071 and 0.200 were agreed by experts and accepted. As well, the experts' agreement percentage of each item is between $88.88 \%$ and $100 \%$ indicated that the experts agreed with these items. Item LC7 however, was rejected due to low (d) threshold value and experts' percentage of agreement, hence, failed to achieve the benchmark values of the analysis. The overall (d) threshold value and the percentage of experts' agreement of the construct were at 0.149 and $89.50 \%$ respectively. 
INTERNATIONAL JOURNAL OF ACADEMIC RESEARCH IN BUSINESS AND SOCIAL SCIENCES Vol. 9, No. 3, March, 2019, E-ISSN: 222 2-6990 ¿ 2019 HRMARS

Table 3

SHIFT IN LEARNING CULTURE (LC) CONSTRUCT THRESHOLD VALUE (D), PERCENTAGE OF EXPERTS' CONSENSUS, AND DEFUZZIFICATION

\begin{tabular}{|c|c|c|c|c|c|c|c|c|c|}
\hline \multirow{2}{*}{ EXPERT } & \multicolumn{9}{|c|}{ ITEM } \\
\hline & LC1 & $\mathrm{LC2} 2$ & $\mathbf{L C 3}$ & LC4 & LCE. & LC6 & LC7 & LC8 & LC9 \\
\hline 1 & 0.2 & 0.1 & 0.1 & 0.2 & 0.2 & 0.2 & 0.4 & 0.3 & 0.1 \\
\hline 2 & 0.4 & 0.2 & 0.2 & 0.1 & 0.1 & 0.1 & 0.1 & 0.0 & 0.2 \\
\hline 3 & 0.1 & 0.2 & 0.1 & 0.1 & 0.2 & 0.1 & 0.3 & 0.0 & 0.1 \\
\hline 4 & 0.2 & 0.1 & 0.2 & 0.1 & 0.1 & 0.1 & 0.1 & 0.0 & 0.2 \\
\hline 5 & 0.2 & 0.1 & 0.1 & 0.2 & 0.2 & 0.1 & 0.3 & 0.0 & 0.1 \\
\hline 6 & 0.2 & 0.1 & 0.1 & 0.1 & 0.4 & 0.1 & 0.1 & 0.0 & 0.1 \\
\hline 7 & 0.1 & 0.1 & 0.1 & 0.2 & 0.1 & 0.2 & 0.1 & 0.0 & 0.1 \\
\hline 8 & 0.2 & 0.1 & 0.1 & 0.2 & 0.2 & 0.2 & 0.1 & 0.0 & 0.1 \\
\hline 9 & 0.2 & 0.1 & 0.2 & 0.1 & 0.2 & 0.2 & 0.4 & 0.3 & 0.1 \\
\hline 10 & 0.1 & 0.2 & 0.2 & 0.1 & 0.4 & 0.1 & 0.1 & 0.0 & 0.1 \\
\hline 11 & 0.1 & 0.1 & 0.2 & 0.1 & 0.1 & 0.1 & 0.1 & 0.0 & 0.2 \\
\hline 12 & 0.1 & 0.2 & 0.5 & 0.1 & 0.1 & 0.1 & 0.3 & 0.0 & 0.2 \\
\hline 13 & 0.2 & 0.1 & 0.1 & 0.2 & 0.2 & 0.1 & 0.1 & 0.0 & 0.1 \\
\hline 14 & 0.1 & 0.2 & 0.2 & 0.1 & 0.4 & 0.4 & 0.1 & 0.0 & 0.2 \\
\hline 15 & 0.1 & 0.1 & 0.1 & 0.1 & 0.2 & 0.2 & 0.1 & 0.0 & 0.1 \\
\hline 16 & 0.2 & 0.1 & 0.1 & 0.1 & 0.4 & 0.4 & 0.3 & 0.3 & 0.2 \\
\hline 17 & 0.2 & 0.1 & 0.1 & 0.1 & 0.1 & 0.1 & 0.1 & 0.2 & 0.1 \\
\hline 18 & 0.2 & 0.1 & 0.1 & 0.1 & 0.1 & 0.1 & 0.1 & 0.2 & 0.1 \\
\hline $\mathrm{d}$ value for each item & 0.172 & 0.129 & 0.171 & 0.136 & 0.200 & 0.161 & 0.142 & 0.071 & 0.143 \\
\hline d value of construct & \multicolumn{8}{|c|}{0.149} & \\
\hline No. of Item $\mathrm{d} \leq 0.2$ & 17 & 18 & 17 & 18 & 14 & 16 & 12 & 15 & 18 \\
\hline$\%$ of each Item $\mathrm{d} \leq 0.2$ & 94.44 & 100 & 94.44 & 100 & 77.77 & 88.88 & 66.67 & 83.33 & 100 \\
\hline$\%$ of Construct & \multicolumn{9}{|c|}{89.50} \\
\hline Fuzzy Evaluation & 12.600 & 13.400 & 12.800 & 12.200 & 11.600 & 11.600 & \multirow{3}{*}{ Reject } & 11.200 & 13.200 \\
\hline Average of Fuzzy No. & 0.700 & 0.744 & 0.711 & 0.678 & 0.644 & 0.644 & & 0.622 & 0.733 \\
\hline Rank & 4 & 1 & 3 & 5 & 6 & 7 & & 8 & 2 \\
\hline
\end{tabular}

Table 4

INTENTIONAL CONTENT (IC) CONSTRUCT THRESHOLD VALUE (D), PERCENTAGE OF EXPERTS' CONSENSUS, AND DEFUZZIFICATION

\begin{tabular}{|c|c|c|c|c|c|c|c|c|c|c|}
\hline \multirow{2}{*}{ EXPERT } & \multicolumn{10}{|c|}{ ITEM } \\
\hline & IC 1 & IC 2 & IC 3 & IC 4 & IC 5 & IC 6 & IC 7 & IC 8 & IC 9 & IC 10 \\
\hline 1 & 0.0 & 0.2 & 0.2 & 0.1 & 0.2 & 0.2 & 0.2 & 0.2 & 0.2 & 0.2 \\
\hline 2 & 0.3 & 0.1 & 0.1 & 0.2 & 0.1 & 0.1 & 0.2 & 0.1 & 0.1 & 0.1 \\
\hline 3 & 0.0 & 0.1 & 0.1 & 0.2 & 0.1 & 0.2 & 0.2 & 0.2 & 0.1 & 0.2 \\
\hline 4 & 0.0 & 0.2 & 0.2 & 0.1 & 0.1 & 0.1 & 0.2 & 0.1 & 0.1 & 0.1 \\
\hline 5 & 0.3 & 0.1 & 0.1 & 0.1 & 0.1 & 0.1 & 0.2 & 0.2 & 0.2 & 0.1 \\
\hline 6 & 0.3 & 0.1 & 0.1 & 0.2 & 0.2 & 0.1 & 0.2 & 0.2 & 0.2 & 0.2 \\
\hline 7 & 0.0 & 0.1 & 0.1 & 0.1 & 0.1 & 0.1 & 0.2 & 0.1 & 0.2 & 0.1 \\
\hline 8 & 0.3 & 0.2 & 0.2 & 0.1 & 0.2 & 0.2 & 0.2 & 0.2 & 0.2 & 0.2 \\
\hline 9 & 0.3 & 0.2 & 0.2 & 0.1 & 0.2 & 0.2 & 0.2 & 0.2 & 0.2 & 0.2 \\
\hline 10 & 0.0 & 0.1 & 0.1 & 0.2 & 0.1 & 0.1 & 0.2 & 0.1 & 0.4 & 0.1 \\
\hline 11 & 0.0 & 0.1 & 0.1 & 0.2 & 0.4 & 0.1 & 0.2 & 0.1 & 0.1 & 0.4 \\
\hline 12 & 0.6 & 0.1 & 0.1 & 0.2 & 0.7 & 0.1 & 0.2 & 0.1 & 0.4 & 0.1 \\
\hline 13 & 0.0 & 0.1 & 0.1 & 0.2 & 0.1 & 0.1 & 0.2 & 0.2 & 0.2 & 0.2 \\
\hline 14 & 0.3 & 0.2 & 0.2 & 0.1 & 0.2 & 0.4 & 0.2 & 0.4 & 0.1 & 0.1 \\
\hline 15 & 0.0 & 0.2 & 0.2 & 0.1 & 0.2 & 0.2 & 0.2 & 0.2 & 0.2 & 0.2 \\
\hline 16 & 0.6 & 0.4 & 0.4 & 0.2 & 0.1 & 0.1 & 0.2 & 0.4 & 0.4 & 0.4 \\
\hline 17 & 0.6 & 0.1 & 0.1 & 0.1 & 0.1 & 0.1 & 0.2 & 0.1 & 0.2 & 0.2 \\
\hline 18 & 0.3 & 0.2 & 0.2 & 0.1 & 0.2 & 0.2 & 0.2 & 0.2 & 0.2 & 0.1 \\
\hline $\mathrm{d}$ value for each item & 0.224 & 0.167 & 0.158 & 0.151 & 0.185 & 0.147 & 0.153 & 0.187 & 0.200 & 0.181 \\
\hline d value of construct & \multicolumn{10}{|c|}{0.176} \\
\hline No. of Item $\mathrm{d} \leq 0.2$ & 8 & 18 & 17 & 18 & 16 & 17 & 18 & 16 & 15 & 16 \\
\hline$\%$ of each Item $\mathrm{d} \leq 0.2$ & 44.44 & 100.00 & 94.44 & 100.00 & 88.89 & 94.44 & 100.00 & 88.89 & 83.33 & 88.27 \\
\hline$\%$ of Construct & \multicolumn{10}{|c|}{88.27} \\
\hline Fuzzy Evaluation & \multirow{3}{*}{ Reject } & 12.267 & 12.000 & 12.800 & 11.600 & 11.800 & 12.600 & 12.200 & 12.200 & 12.000 \\
\hline Average of Fuzzy No. & & 0.681 & 0.667 & 0.711 & 0.644 & 0.656 & 0.700 & 0.678 & 0.678 & 0.667 \\
\hline Rank & & 3 & 6 & 1 & 9 & 8 & 2 & 4 & 5 & 7 \\
\hline
\end{tabular}

The construct 'Intentional Content' (IC) had ten items as shown in table 4. The (d) threshold value of each item (IC2; IC3; IC4; IC5; IC6; IC7; IC8; IC9; and IC10) respectively was accepted by the experts. The percentage of experts' agreement of the accepted items are $100 \%$ for IC2, IC4, IC7, $94.44 \%$ for 
INTERNATIONAL JOURNAL OF ACADEMIC RESEARCH IN BUSINESS AND SOCIAL SCIENCES Vol. 9, No. 3, March, 2019, E-ISSN: 222 2-6990 @ 2019 HRMARS

IC3 and IC6, 88.89\% for IC5 and IC8, 88.27\% (IC 10) and $83.33 \%$ (IC9) respectively. IC1 on the other hand, was rejected due to low values. The overall (d) construct threshold value and percentage were agreed and accepted at 0.175 and $88.27 \%$ respectively.

Table 5

PROFESSIONAL EDUCATORS (PE) CONSTRUCT THRESHOLD VALUE (D), PERCENTAGE OF EXPERTS' CONSENSUS, AND DEFUZZIFICATION

\begin{tabular}{|c|c|c|c|c|c|c|c|c|c|c|c|c|c|c|c|}
\hline \multirow{2}{*}{ EXPERT } & \multicolumn{15}{|c|}{ ITEMS } \\
\hline & PE1 & PE2 & $\mathrm{PE} 3$ & PE4 & PE5 & PE6 & PE7 & PE8 & PE9 & PE10 & PE11 & PE12 & PE13 & PE14 & PE15 \\
\hline 1 & 0.1 & 0.0 & 0.1 & 0.2 & 0.2 & 0.1 & 0.3 & 0.3 & 0.2 & 0.1 & 0.1 & 0.2 & 0.2 & 0.2 & 0.2 \\
\hline 2 & 0.1 & 0.0 & 0.1 & 0.1 & 0.1 & 0.2 & 0.1 & 0.0 & 0.1 & 0.2 & 0.2 & 0.1 & 0.1 & 0.1 & 0.1 \\
\hline 3 & 0.1 & 0.0 & 0.2 & 0.4 & 0.4 & 0.2 & 0.3 & 0.0 & 0.1 & 0.1 & 0.2 & 0.1 & 0.1 & 0.2 & 0.2 \\
\hline 4 & 0.1 & 0.0 & 0.1 & 0.2 & 0.1 & 0.2 & 0.1 & 0.0 & 0.1 & 0.2 & 0.2 & 0.1 & 0.1 & 0.1 & 0.1 \\
\hline 5 & 0.2 & 0.0 & 0.2 & 0.1 & 0.1 & 0.1 & 0.1 & 0.0 & 0.2 & 0.2 & 0.1 & 0.1 & 0.2 & 0.2 & 0.1 \\
\hline 6 & 0.2 & 0.3 & 0.2 & 0.2 & 0.1 & 0.2 & 0.1 & 0.3 & 0.7 & 0.2 & 0.1 & 0.1 & 0.2 & 0.1 & 0.2 \\
\hline 7 & 0.1 & 0.0 & 0.1 & 0.1 & 0.2 & 0.1 & 0.1 & 0.0 & 0.2 & 0.1 & 0.2 & 0.2 & 0.1 & 0.1 & 0.1 \\
\hline 8 & 0.2 & 0.3 & 0.2 & 0.2 & 0.2 & 0.1 & 0.3 & 0.3 & 0.2 & 0.1 & 0.1 & 0.2 & 0.2 & 0.2 & 0.2 \\
\hline 9 & 0.2 & 0.3 & 0.2 & 0.2 & 0.2 & 0.1 & 0.3 & 0.3 & 0.2 & 0.1 & 0.1 & 0.2 & 0.2 & 0.2 & 0.2 \\
\hline 10 & 0.1 & 0.3 & 0.1 & 0.1 & 0.1 & 0.2 & 0.1 & 0.3 & 0.4 & 0.1 & 0.1 & 0.2 & 0.1 & 0.1 & 0.1 \\
\hline 11 & 0.1 & 0.3 & 0.1 & 0.1 & 0.1 & 0.2 & 0.1 & 0.0 & 0.1 & 0.2 & 0.2 & 0.1 & 0.4 & 0.1 & 0.4 \\
\hline 12 & 0.1 & 0.0 & 0.1 & 0.1 & 0.1 & 0.2 & 0.1 & 0.0 & 0.1 & 0.2 & 0.2 & 0.4 & 0.1 & 0.1 & 0.1 \\
\hline 13 & 0.1 & 0.0 & 0.2 & 0.2 & 0.2 & 0.1 & 0.1 & 0.0 & 0.1 & 0.2 & 0.1 & 0.2 & 0.1 & 0.1 & 0.1 \\
\hline 14 & 0.1 & 0.3 & 0.1 & 0.1 & 0.4 & 0.1 & 0.4 & 0.0 & 0.1 & 0.1 & 0.2 & 0.1 & 0.1 & 0.2 & 0.1 \\
\hline 15 & 0.2 & 0.3 & $\begin{array}{l}0.2 \\
\end{array}$ & 0.2 & 0.2 & 0.1 & 0.3 & 0.0 & 0.2 & 0.1 & 0.1 & 0.2 & 0.2 & 0.2 & 0.1 \\
\hline 16 & 0.1 & 0.3 & 0.1 & 0.1 & 0.1 & 0.1 & 0.1 & 0.0 & 0.1 & 0.2 & 0.2 & 0.2 & 0.1 & 0.1 & 0.1 \\
\hline 17 & 0.2 & 0.3 & 0.2 & 0.1 & 0.1 & 0.1 & 0.4 & 0.0 & 0.2 & 0.1 & 0.1 & 0.2 & 0.2 & 0.2 & 0.2 \\
\hline 18 & 0.2 & 0.3 & 0.2 & 0.2 & 0.2 & 0.1 & 0.3 & 0.3 & 0.2 & 0.1 & 0.1 & 0.2 & 0.2 & 0.2 & 0.2 \\
\hline $\begin{array}{l}\text { d value for } \\
\text { each item }\end{array}$ & 0.14 & 0.17 & 0.15 & 0.17 & 0.17 & 0.15 & 0.15 & 0.11 & 0.20 & 0.15 & 0.15 & 0.17 & 0.16 & 0.15 & 0.15 \\
\hline $\begin{array}{l}\mathrm{d} \text { value of } \\
\text { construct }\end{array}$ & \multicolumn{15}{|c|}{0.157} \\
\hline $\begin{array}{l}\text { No. of Item } d \leq \\
0.2\end{array}$ & 18 & 7 & 18 & 17 & 16 & 18 & 10 & 12 & 16 & 18 & 18 & 17 & 17 & 18 & 17 \\
\hline $\begin{array}{l}\% \text { of each Item } \\
d \leq 0.2\end{array}$ & 100.0 & 38.9 & 100.0 & 94.4 & 88.9 & 100.0 & 55.6 & 66.7 & 88.9 & 100.0 & 100.0 & 94.4 & 94.4 & 100.0 & 94.4 \\
\hline$\%$ of Construct & \multicolumn{15}{|c|}{87.8} \\
\hline $\begin{array}{l}\text { Fuzzy } \\
\text { Evaluation }\end{array}$ & 12.2 & \multirow{3}{*}{ Reject } & 12.6 & 12.2 & 11.8 & 13.0 & \multirow{3}{*}{ Reject } & \multirow{3}{*}{ Reject } & 11.8 & 12.8 & 12.8 & 12.6 & 12.2 & 12.6 & 12.0 \\
\hline $\begin{array}{l}\text { Average of } \\
\text { Fuzzy No. }\end{array}$ & 0.68 & & 0.70 & 0.68 & 0.66 & 0.72 & & & 0.66 & 0.71 & 0.71 & 0.70 & 0.68 & 0.70 & 0.67 \\
\hline Rank & 10 & & 5 & 7 & 11 & 1 & & & 12 & 3 & 2 & 6 & 8 & 4 & 9 \\
\hline
\end{tabular}

Finally, table 5 details the 'Professional Educators' (PE) construct FDM analyses. The (d) threshold value for each accepted item (PE1; PE3; PE4; PE5; PE6; PE9; PE10; PE11; PE12; PE13; PE14; and PE15) was between 0.140 and 0.195 . The experts' agreement percentage were varied between $100 \%$ (PE1; PE3; PE6; PE10; PE11; and PE14), 94.4\% (PE4; PE12; PE13; and PE15), and 88.9\% (PE5 and PE9). Unfortunately, three items with the values of 0.170 (PE2), 0.154 (PE7) and 0.112 (PE8) and their respective percentage of $39 \%, 56 \%$ and $67 \%$ were rejected from the list. The overall construct (d) threshold value and experts' agreement percentage are 0.157 and $87.8 \%$.

\section{Conclusion}

The experts agreed that the developed flip learning framework required four essential constructs with 36 items to implement the approach in the targeted context. The results of the analyses using FDM showed a drop of six items from the earlier list of items: Flexible environments ( 1 item), Shift in Learning Culture (1 item), Intentional Content ( 1 item) and Professional Educators ( 3 items). Utmost, the results confirmed the commonality between the participated experts and the work by Hamdan et al. (2013). All parties regarded that the four educators and learning related 
constructs and its items as being the strategic elements for the development of a flipped learning framework in an ESL context. The constructs and items encompassed strategic interdependent parameters of technologies, pedagogies, teaching and learning experience, for a complete $21^{\text {st }}$ century teaching and learning spectrum.

The contributions of the study are the establishment of factors that is relevant and important in developing a framework for the Flipped learning approach in an ESL context. The factors investigated in the study is in line with principals of the Industrial Revolution 4.0 pivotal factors, which are: communication, collaboration, critical and creative thinking. What is apparent, is that the four principals mentioned are embedded in the factors investigated for this study and thus making it relevant in the discussions and development of any educational technology-based investigations. More importantly, the application of the Flipped learning approach in an ESL context can now be done effectively as the factors that ensure effective implementation that entails the educator's and learning perspective are identified. This ensures the flipped lessons are guided and meaningful in its implementation.

\section{References}

Baepler, P., Walker, J. D. \& Driessen, M. (2014). It's not about seat time: Blending, flipping, and efficiency in active learning classrooms. Computers and Education, 78, 227-236.

Bergmann, J., \& Sams, A. (2014). Flipped Learning: Gateway to Student Engagement. International Society for Technology in Education.

Bergman, J., \& Sams, A. (2012). Flipped your classroom: Reach every student in every class everyday. Washington, DC: International Society for Technology in Education.

Berrett, D. (2012). How "Flipping" the Classroom Can Improve the Traditional Lecture. The Chronicle of Higher Education, 1-22. Retrieved from http://chronicle.com/article/How-Flippedping-theClassroom/130857/

Butt, A. (2014). Student views on the use of a flipped classroom approach: evidence from Australia. Business Education \& Accreditation, 6(1), 33-43

Chen Y., Wang, Y., \& Chen, N. S. (2014). Is flip enough? Or should we use the flipped model instead? Computers and Education, 79, 16-27.

Deslauriers, L., Schelew, E., \& Wieman, C. (2011). Improved learning in a large-enrollment physics class. Science, 332, pp. 862-864.

Embi, M. A. (2014). Blended \& Flipped Learning: Case Studies in Malaysian HEls. 1st Edition. Kuala Lumpur: UKM.

Enfield, J. (2013). Looking at the impact of the flipped classroom model of instruction on undergraduate multimedia students at CSUN. TechTrends: Linking Research \& Practice to Improve Learning, 57(6), 14-27.

Hamdan, N., McKnight, P., McKnight, K., \& Arfstrom, K. (2013). A review of flipped learning. Retrieved from the Flipped Learning Network. Retrieved March 19, 2014 from http://flippedlearning.org/ cms/lib07/VA01923112/ Centricity/Domain/41/LitReview_FlippedLearning.pdf.

Harun, F. \& Hussin, S. (2017). The acceptance of flipped language learning (FLL): A study of 
engineering students at Technical Matriculation College. International Journal of Applied Engineering Research, 12(24), 14495-14504.

Juhary, J. \& Amir, A. F. (2015). Flipped Classroom at the Defence University : An Introduction.

Kenna, donald christian. (2014). A study of the effect the flipped classroom model on student selfefficacy. Dissetation thesis. Faculty of the North Dakota State University of Agriculture and Applied Science, North Dakota State University.

Lowell, J., \& Verleger, M. (2013). The flipped classroom: A survey of the research. ASEE Annual Conference. Atlanta.

Malaysia Education Blueprint, M. (2013). Malaysia Education Blueprint 2013 - 2025. Education

Malganova, I. \& Rahkimova, A. (2016). E-Learning Practice Using Moodle by Leading Universities in the Russian Region. Academy of Strategic Management Journal, 15 (Special Issue), 14-19.

Ministry of Education Malaysia (MOE) (2015). Malaysia Education Blueprint 2015-2025 (Higher Education). Putrajaya.

O'Flaherty, J. \& Phillips, C. (2015). The use of flipped classrooms in higher education: A scoping review. The Internet and Higher Education, 25, 85-95.

Osman, S. Z. M, Jamaludin, R. \& Mokhtar, N. E. (2014). Flipped Classroom and Traditional Classroom: Lecturer and Student Perceptions between Two Learning Cultures, a Case Study at Malaysian Polytechnic. International Education Research, 2(4), 16-25. doi:10.12735/ier.v2i4p16

Sankey, M.D. \& Hunt, L. (2013). Using technology to enable flipped classrooms whilst sustaining sound pedagogy. In ASCILITE-Australian Society for Computers in Learning in Tertiary Education Annula conference, pp. 785-795. Australasian Society for Computers in Learning in Tertiary Education, 2013.

Talley, C. \& Scherer, S. (2013). The enhanced flipped classroom: increasing academic performance with student-recorded lectures and practice testing in a 'flipped' stem course. Journal Of Negro Education, 82(3), 339-347.

Walter-Perez and Dong, Jianyu. (2012). Flipping the classroom: How to embed inquiry and design projects into a digital engineering lecture. Paper presented at ASEE PSW Section Conference, California Polytechnic State University, San Luis Obispo. 